\title{
Ion Diffusion Behavior between Fracturing Water and Shale and Its Potential Influence on Production
}

\author{
Yinghao Shen, ${ }^{1,2}$ Zhaopeng Zhu, ${ }^{3}$ Peng Shi, ${ }^{4}$ Hongkui Ge, ${ }^{1}$ and Zhihui Yang ${ }^{1}$ \\ ${ }^{1}$ China University of Petroleum, Beijing, China \\ ${ }^{2}$ Texas Tech University, Lubbock, TX, USA \\ ${ }^{3}$ PetroChina Jilin Oilfield Company, Songyuan, China \\ ${ }^{4}$ Research Institute of Shaanxi Yanchang Petroleum "Group" Co., Ltd., Xian, Shaanxi, China \\ Correspondence should be addressed to Yinghao Shen; yinghao.shen@ttu.edu
}

Received 31 May 2017; Accepted 6 July 2017; Published 7 August 2017

Academic Editor: Jae Ryang Hahn

Copyright (c) 2017 Yinghao Shen et al. This is an open access article distributed under the Creative Commons Attribution License, which permits unrestricted use, distribution, and reproduction in any medium, provided the original work is properly cited.

\begin{abstract}
Water imbibition, conductivity measurements, and ion identification were performed to investigate ion diffusion behavior between slick water and shale for large-scale hydraulic fracturing. The results indicated that there was strong ion exchange between water and shale. The ion concentration in water increases with fracture complexity and is dependent on the salinity of fracturing fluids. This implies that fracturing effects could be forecast from flow-back fluid ion concentrations after large-scale slick water fracturing. Higher levels of ion diffusion imply the presence of larger fracturing areas and higher level of fracture density for a similar reservoir. The mechanism of ion diffusion and the corresponding effects on IOR (increased oil recovery) based on a field example are discussed.
\end{abstract}

\section{Introduction}

The increasing demand for energy has prompted a need to find economical ways of developing unconventional resources, such as shale gas, globally. Shale oil and gas reservoirs are of relatively low permeability and porosity, and most hydrocarbons are stored in their tight matrixes [1,2]. Largescale hydraulic fracturing serves as an effective means of exploiting shale formation. In view of the performance of shale hydraulic fracturing methods, a large amount of fracturing fluid (generally more than $30 \%$ ) is retained in shale formations after flow back [3]. The interaction between water and shale plays an important role in large-scale hydraulic fracturing [4-6]. Water has an enormous influence on the mechanical behaviors [7], effective flow channels [8], flow-back methods [9], and gas production patterns [10] of unconventional reservoirs. Fracturing fluids imbibition process and way in which slick water enters formations have received considerable attention [11, 12]. High capillary forces are recognized as a major force because there are abundance nanopores and always ultralow initial water saturation in shale $[13,14]$. Series experiments have been conducted to investigate related physical processes [15-18]. Fractal theory has been used in interaction studies and gas proving that ultracomplex microstructures render interactions between fracturing fluids and shale matrixes much more complex than those of conventional reservoirs $[19,20]$.

The chemical action between slick water and shale has recently attracted attentions. Osmotic pressure is recognized as an important driving force for water imbibition and shale oil production [21]. The abundant content of clay minerals serves as foundation for clay-chemical effects. Recently, a model considering osmotic effects has shown that chemical actions play a key role in interactions between slick water and shale [22]. Typically, salinity control is one important way to enhance oil recovery based on the oilfield chemistry $[23,24]$. However, the impacts of fracturing fluid salinity on IOR (increasing oil recovery) have not received enough attention. Ion exchange between slick water and shale must be investigated to understand the chemical processes involved.

In this study, we conducted water imbibition, conductivity measurement, and ion identification experiments to examine patterns of the ion exchange between slick water and shale. Slick water is here defined as the main fracturing 
TABLE 1: Mineral concentrations (wt\%) of the shale samples as determined by X-ray Diffraction.

\begin{tabular}{lc}
\hline Sample & Shale \\
\hline Calcite & 6 \\
Quartz & 44 \\
Dolomite & 3 \\
Pyrite & 3 \\
Feldspar & 2 \\
Illite & 23 \\
Chlorite & 12 \\
Illite/smectite & 7 \\
\hline
\end{tabular}

fluid for shale oil and gas development $[25,26]$, and the main component is water, the percentage of which always exceeds $98 \%$. The aim of this study was to determine ion diffusion performance between shale and slick water in Longmaxi Shale in China. The effects of fractures in rock, slick water with different salinity, and different clay content are considered. Related mechanisms and potential applications are discussed based on actual field studies conducted in a shale gas field of southern China.

\section{Experiment}

2.1. Sample Description and Preparation. Shale samples in this study are from the Longmaxi Shale Formation of Lower Silurian in the Sichuan Basin of China. The samples were cut from one large outcrop, the size of which is approximately $80 \mathrm{~cm} \times 80 \mathrm{~cm} \times 80 \mathrm{~cm}$. The shale sample is composed of a relatively high proportion of quartz. Clay mineral type and content were tested by X-ray diffraction (XRD) using an Empyrean diffractometer provided by a third test company. Corresponding results are shown in Table 1 . Backscattered electron images were obtained for the thin slices of the shale samples using NanoLab 650 (FEI, USA), a highly accurate Scanning Electron Microscope (SEM) stationed at China University of Petroleum, Beijing. According to XRD results, quartz and clay minerals are the most abundant minerals in the shale samples as confirmed by Figure 1. The main clay minerals found are illite and chlorite. A small amount of smectite is found in interlayers, denoting the presence of few swelling clay minerals.

The porosity of the shale samples ranges from $6 \%$ to $8 \%$. Porosity was measured using a helium porosimeter developed by Core lab. The permeability of the shale samples ranges from $4 \times 10^{-4} \mathrm{mD}$ to $7 \times 10^{-4} \mathrm{mD}$ as measured from an ultralow permeability measurement instrument (YRDCP200 type). The permeability was measured as pulse-decay permeability with a confining pressure $8 \mathrm{MPa}$ and pore pressure $5 \mathrm{MPa}$. The rocks exhibit a bimodal pore-size distribution of both micropores and nanopores that vary in size from $30 \mu \mathrm{m}$ to $60 \mu \mathrm{m}$ and from $1.7 \mathrm{~nm}$ to $20 \mathrm{~nm}$, respectively [27].

Figure 1 shows shale backscattered electron images. The main components are quartz and clay. The image shows welldeveloped pores in organic matter, a major characteristic of
Longmaxi Shale. Direct measurements of pore sizes within the organic matter show pore sizes of the nanoscale.

2.2. Experimental Procedures. The experiment equipment mainly includes a conductivity meter, burette, and balance. Water electrical conductivity was measured based on a multifunctional conductivity measurement produced by METTLER-TOLEDO (Type: SevenExcellence S700). The electrode used is a normal solution conductivity electrode with a precision of $0.1 \mathrm{mS} / \mathrm{cm}-2000 \mathrm{mS} / \mathrm{cm}( \pm 0.5 \%)$ and a suitable temperature of $-30^{\circ} \mathrm{C}$ to $130^{\circ} \mathrm{C}$. The chemical agent used included silver nitrate solution, $\mathrm{K}_{2} \mathrm{CrO}_{4}$ indicator, hydrochloric acid, phenolphthalein, methyl orange, EDTA standard solution, $\mathrm{NaOH}$ standard solution, calconcarboxylic acid, and ammonium hydroxide.

The environmental temperature was set to $25^{\circ} \mathrm{C}$. The tests were conducted under atmosphere pressure $(0.1 \mathrm{MPa})$. The tests progressed as follows:

(1) Measure the sample weight and place the sample into different liquids.

(2) Measure the conductivity of the liquid with time.

(3) Use the titrimetric method to measure the ion content.

(4) Measure the final sample weight after water imbibition.

To investigate the interaction between water and shale, we used three different schemes to investigate different factors influencing ion diffusion such as contact area, liquid salinity, and fracture density. The samples described blow were collected from one outcrop of the Longmaxi formation, the properties of which are discussed in Section 2.1.

Case 1. Samples of the same size $(1 \mathrm{~cm} \times 2 \mathrm{~cm} \times 3 \mathrm{~cm})$ are placed in distilled water, in low salinity water and in high salinity water. We conduct a test following the measure steps listed above.

Case 2. We obtain samples from one large sample. The curved samples are of two sizes: $1 \mathrm{~cm} \times 1 \mathrm{~cm} \times 1 \mathrm{~cm}$ and $1 \mathrm{~cm} \times$ $2 \mathrm{~cm} \times 3 \mathrm{~cm}$. Rock volumes are the same between 6 samples of the former size and 1 sample of the latter size. However, the six small samples include three fractures (Figure 2). In a similar fashion, 12 small samples, 18 small samples, and the corresponding same-sized large sample are, respectively, tested on as well.

Case 3. We obtain three samples from one large sample. The first includes two pronounced fractures. The second has one smaller fracture and its sample volume is the same as that of the former. The third has one fracture as well and differs from the second in that its volume is slightly smaller than the second (Figure 3).

\section{Results}

The conductivity change found for similar shale samples in the different solutions is shown in Figure 4. The conductivity 


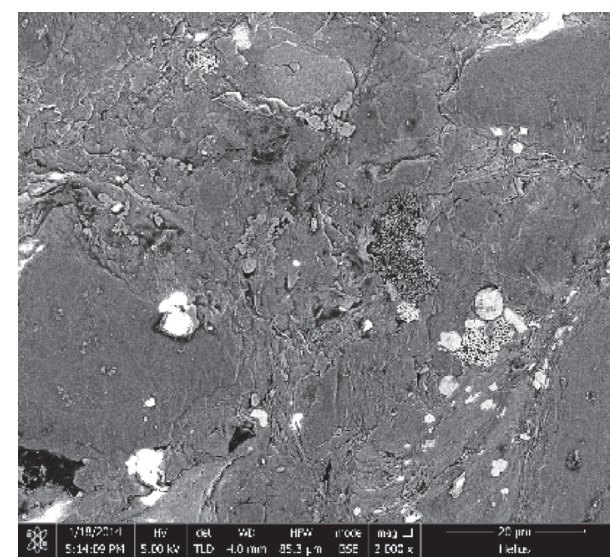

(a)

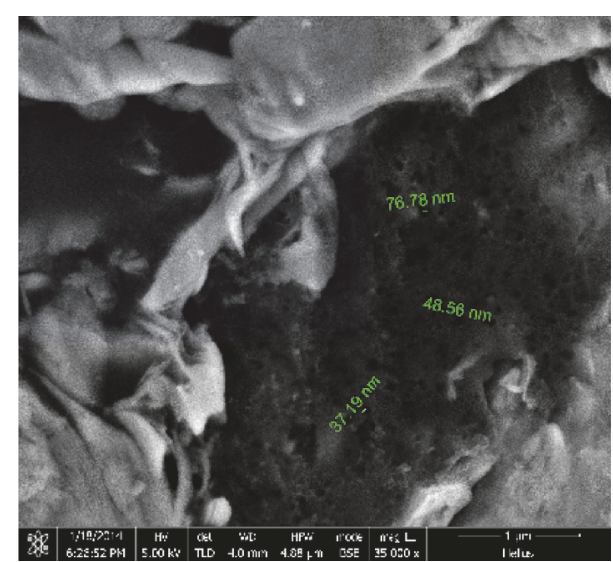

(b)

FIGURE 1: Backscattered electron images of shale samples: (a) SEM image of a lower resolution; (b) SEM image of a higher resolution.

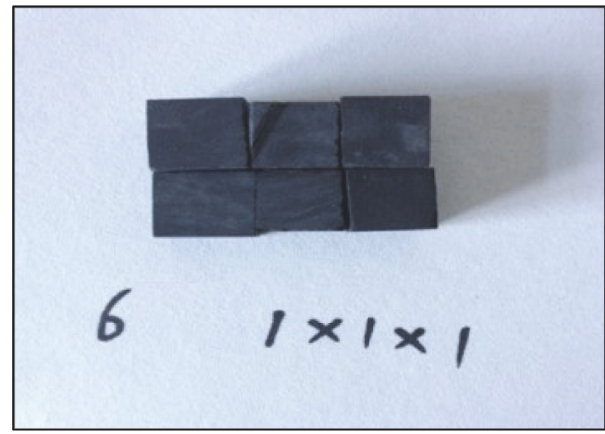

(a)

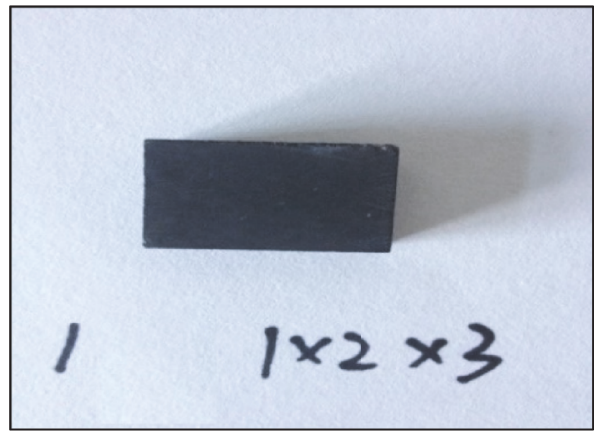

(b)

Figure 2: Shale samples of Case 2. (a) Six small samples $(1 \mathrm{~cm} \times 1 \mathrm{~cm} \times 1 \mathrm{~cm})$; (b) one large sample $(1 \mathrm{~cm} \times 2 \mathrm{~cm} \times 3 \mathrm{~cm})$ of the same volume with six small samples in (a).

increased with time as we placed the samples into the liquids. The conductivity of distilled water and of low salinity slick water increased significantly. However, the conductivity of high salinity slick water increased only slightly. Conductivity changes for distilled water, low salinity water, and high salinity water are $284 \mu \mathrm{S} / \mathrm{cm}, 194 \mu \mathrm{S} / \mathrm{cm}$, and $125 \mu \mathrm{S} / \mathrm{cm}$ after 8 hours, respectively.

The final conductivity changes and imbibed water volume observed are shown in Figure 5. The imbibed water volumes for distilled water, low salinity water, and high salinity water are $0.35 \mathrm{~cm}^{3}, 0.29 \mathrm{~cm}^{3}$, and $0.22 \mathrm{~cm}^{3}$ after 8 hours, respectively. We can see that ions have a considerable effect on water imbibition patterns, as the shale samples are separated by one larger sample. Clearly, the imbibed water volume is proportional to the conductivity change, proving the existence of chemical action between water and shale. Stronger osmotic effects between the sample and water were achieved under higher levels of salinity difference. Osmotic effects increasing the water intake capacities of shale and ion concentrations serve as evidence of this process.

Conductivity changes for the different samples are shown in Figure 6. First, the conductivity of the same sample(s) increased significantly early on and rates declined with time.
Second, the conductivity curve of the three samples shows that the larger sample exhibits a higher level of conductivity for one specific time. Third, the conductivity of the samples simulating fracturing is much greater than that of the whole sample, though the whole volume is the same, indicating that the fracturing considerably influences the interaction between fracturing fluids and shale. For example, the conductivity of 6 samples $(1 \mathrm{~cm} \times 1 \mathrm{~cm} \times 1 \mathrm{~cm})$ is greater than that of one sample $(1 \mathrm{~cm} \times 2 \mathrm{~cm} \times 3 \mathrm{~cm})$. Additionally, conductivity levels increased with sample values.

Figure 7 shows ion content levels for the different conditions. The main ions shown here are $\mathrm{Cl}^{-}$and total cations. $\mathrm{Cl}^{-}$is set as an evaluation object because it is easy to test in the field. We find that ion content levels increase with the number of samples involved and such changes corresponded to changes in conductivity. $\mathrm{Cl}^{-}$content levels are recorded as $201.45 \mathrm{mg} / \mathrm{L}, 403.2 \mathrm{mg} / \mathrm{L}$, and $723.15 \mathrm{mg} / \mathrm{L}$ for 6 samples, 12 samples, and 18 samples, respectively. Total cation contents levels are recorded as $133.45 \mathrm{mg} / \mathrm{L}, 250.45 \mathrm{mg} / \mathrm{L}$, and $514.03 \mathrm{mg} / \mathrm{L}$, respectively.

Figure 8 shows the change in conductivity for three samples cut from one large sample. The trend of conductivity change observed is the same as that observed for the other 


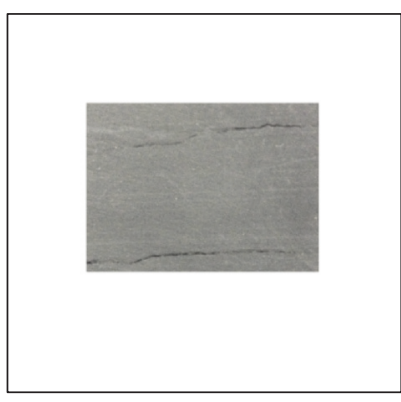

(a)

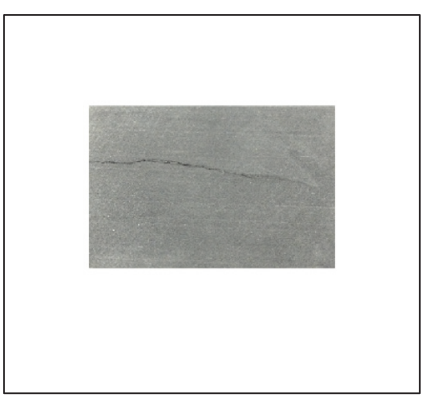

(b)

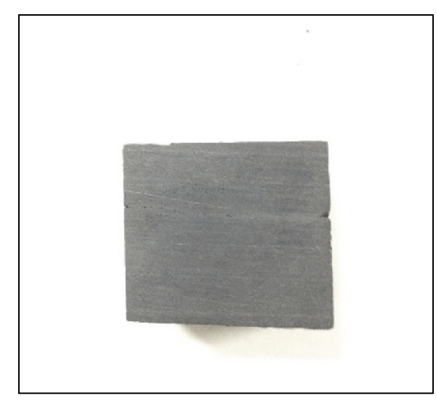

(c)

Figure 3: Shale samples of Case 3. (a) Sample with significant fractures. (b) Sample with limited fractures: the volume is the same as that of the sample shown in (a). (c) Sample with limited fractures: the volume is smaller than that of the sample shown in (a) and (b).

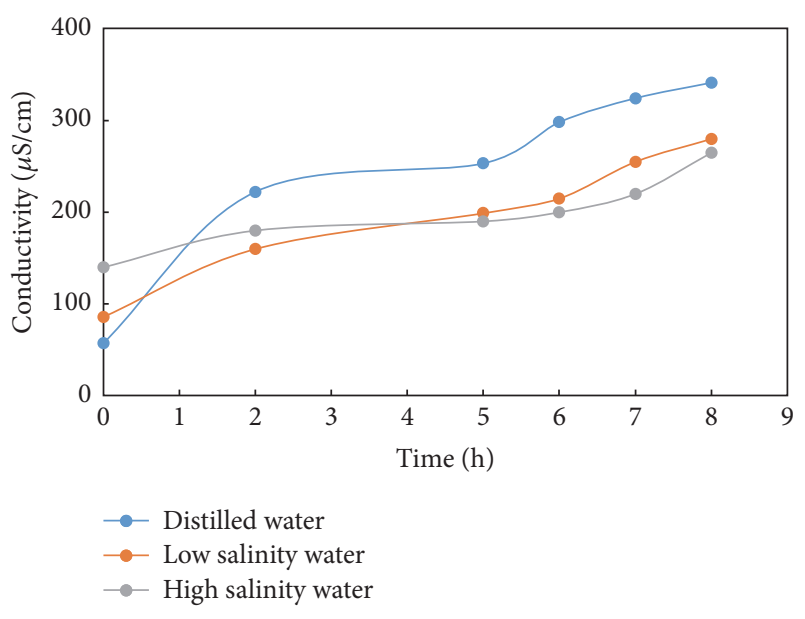

FIGURE 4: Conductivity changes for different solutions for Case 1.

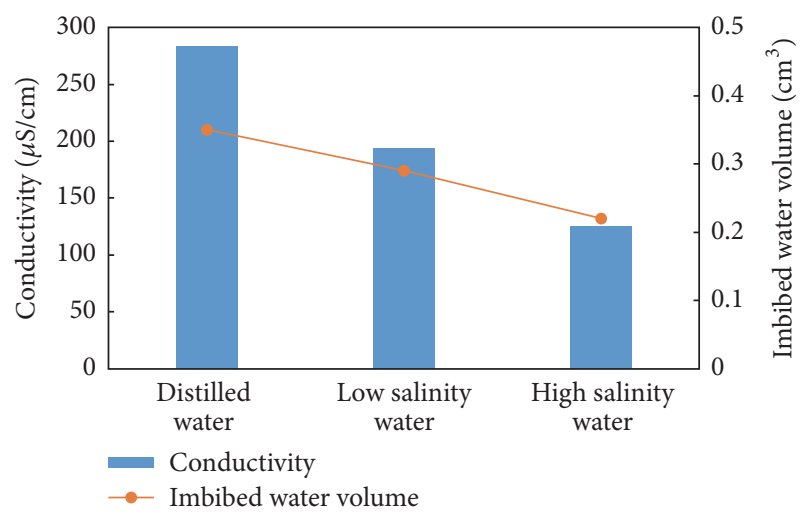

FIGURE 5: Final conductivity changes and imbibed water volumes for Case 1.

samples. The one with more fractures is more conductive than the other two, showing that natural fractures play a significant role in water imbibition. Here, sample 2 and sample 3 present minor differences. The conductivity levels of the three samples are recorded as $1,020 \mu \mathrm{S} / \mathrm{cm}, 666 \mu \mathrm{S} / \mathrm{cm}$,

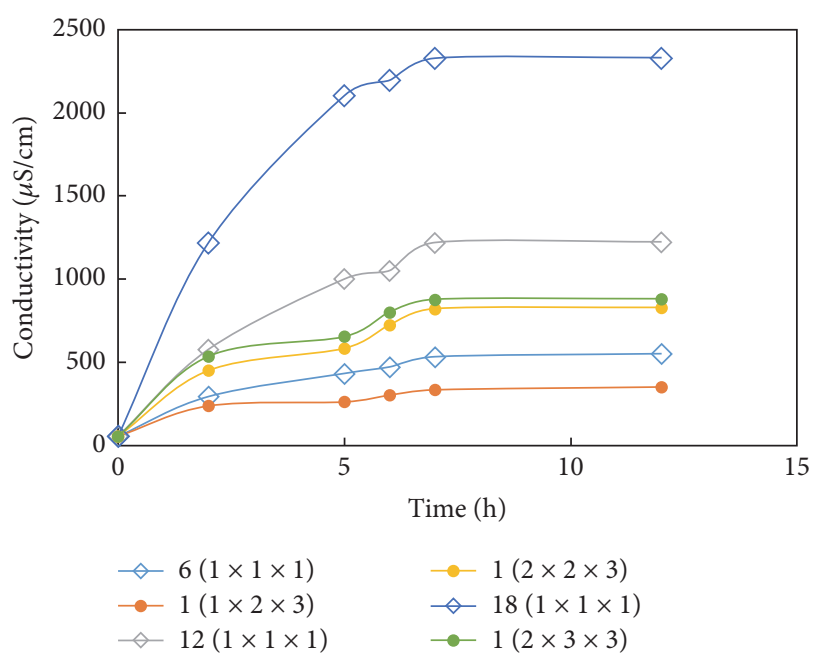

Figure 6: Conductivity changes for different samples for Case 2.

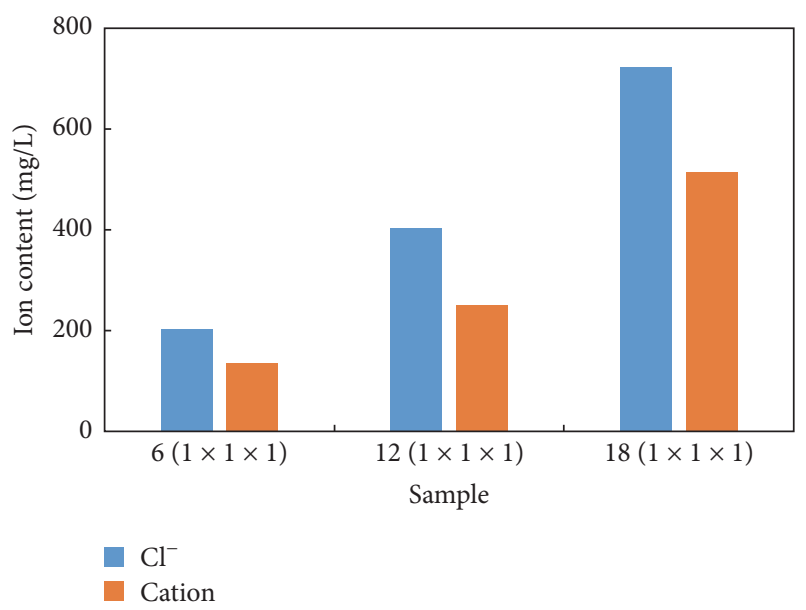

FIGURE 7: Ion content of different samples for Case 2.

and $612 \mu \mathrm{S} / \mathrm{cm}$ after 11 hours for example 1 , example 2 , and example 3 , respectively.

Corresponding ion concentrations shown in Figure 9 exhibit the same conductivity trends. $\mathrm{Cl}^{-}$concentrations are 


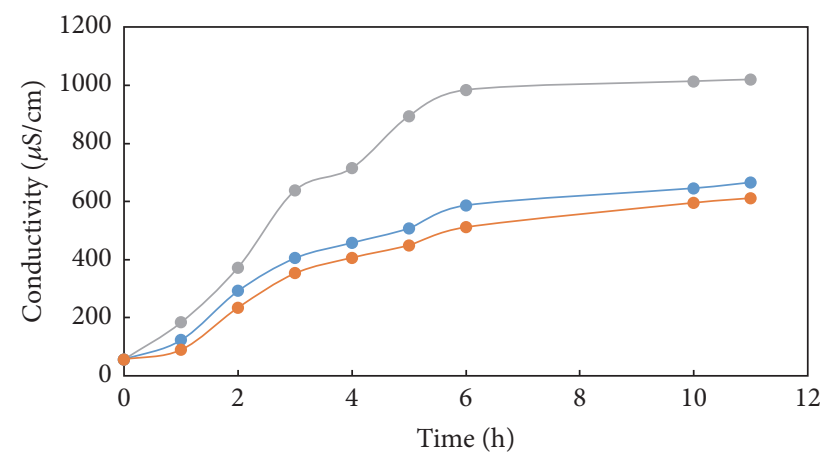

$\longrightarrow$ Sample 1
$\longrightarrow$ Sample 2
$\longrightarrow$ Sample 3

Figure 8: Conductivity changes for the different samples for Case 3.

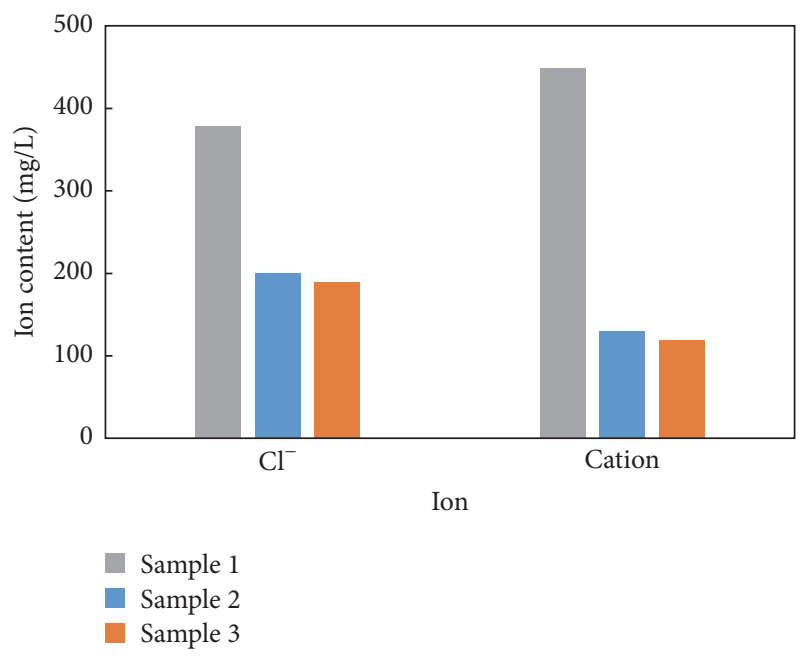

FIGURE 9: Ion content for the different samples for Case 3.

recorded as $378.2 \mathrm{mg} / \mathrm{L}, 199.73 \mathrm{mg} / \mathrm{L}$, and $188.91 \mathrm{mg} / \mathrm{L}$ for sample 1 , sample 2 , and sample 3 , respectively. Ion concentrations of sample 1 are much higher than those of sample 2 and sample 3. It is evident that the difference between sample 2 and sample 3 is minor as well, as these samples are similar in terms of fracture complexity and volume.

\section{Discussion}

Conductivity is defined as the physical quantity representing the ability to conduct electricity from an electrolyte. In most cases, the conductivity value reflects TDS (total dissolved solids) in a solution. Conductivity is traditionally used to measure ion concentrations in industrial solutions. Thus, ion exchange is the main mechanism that operates in the interaction between the slickwater and formation rock. Changes in conductivity in fluids serve as an indication of ion concentration change.

In large-scale hydraulic fracturing formations, ions from formations are derived from two main sources: ions captured by clay minerals and ions in formation water. When fluids come into contact with a formation after hydraulic fracturing, ion exchange occurs between fluids and the formation. The driving force of ion exchange is mainly concentration diffusion resulting from concentration differences between formation fluids and fracturing fluids and from ion exchange controlled by clay minerals. The second driving force is dependent on ion exchange properties of clay minerals. Clay minerals adsorb some cations and anions and these ions remain exchangeable. Generally, exchangeable cation includes $\mathrm{Ca}^{2+}, \mathrm{Mg}^{2+}, \mathrm{H}^{+}, \mathrm{K}^{+},\left(\mathrm{NH}_{4}\right)^{+}$, and $\mathrm{Na}^{+}$and exchangeable anions include $\left(\mathrm{SO}_{4}\right)^{2-}, \mathrm{Cl}^{-}$, and $\left(\mathrm{NO}_{3}\right)^{-}$.

According to our experiments and to ion diffusion theory, ion diffusion between slick water and shale formations is characterized as follows.

(1) Salinity differences between formations and slick water serve as the main driving force for ion diffusion.

The samples we used in the experiments were drawn from the Longmaxi formation in southern China. The formation is composed of typical marine deposit shale. The surrounding deposit environment affords the formation of high salinity relative to the continental shale. The salinity of fracturing fluids is typically lower than that of a formation to decrease liquid friction and to thus improve the penetrability and volume fracturing. Water in the formation is highly saline and clay minerals adsorb more ion. This salinity difference serves as the driving force to ion diffusion. Figure 3 shows that as the difference in salinity levels increases, ion diffusion processes become more pronounced. Furthermore, ion diffusion is always accompanied by water adsorption, whereby higher salinity differences lead to higher amounts of water volume imbibed for Case 1.

(2) The higher cation exchange capacity (CEC) of shale serves as a key driving force for fracturing fluids imbibition and ion exchange.

Shale formations typically include more clay minerals than regular sandstone reservoirs. Clay content levels of Longmaxi Shale in the oriented shale gas field amount to approximately $40 \%$. The CEC value increases with increases in clay content and especially as smectite and ion exchange potential levels increase. Water is imbibed into the interlayers of clay minerals, accelerating ion diffusion.

(3) Contact areas and fracture complexity are critical factors that influence the ion diffusion in a specific environment.

Salinity and clay content and time patterns are stable in a specific reservoir. When slick water is pumped into a reservoir, the interaction between slick water and formations is mainly controlled by the contact area, which is supported by Figures 5 and 6. Large-scale slick water fracturing generates higher levels of volume fractures. Higher levels of fracture density adds the contact areas between water and rock (Figures 5 and 7). In turn, ion diffusion is more pronounced at contact areas and fracture complexity levels in turn increase. During and after fracturing, ion diffusion occurs through interactions between fracturing fluids and formation rock and this effect is reflected at the ion concentrations in flowback fluids. 


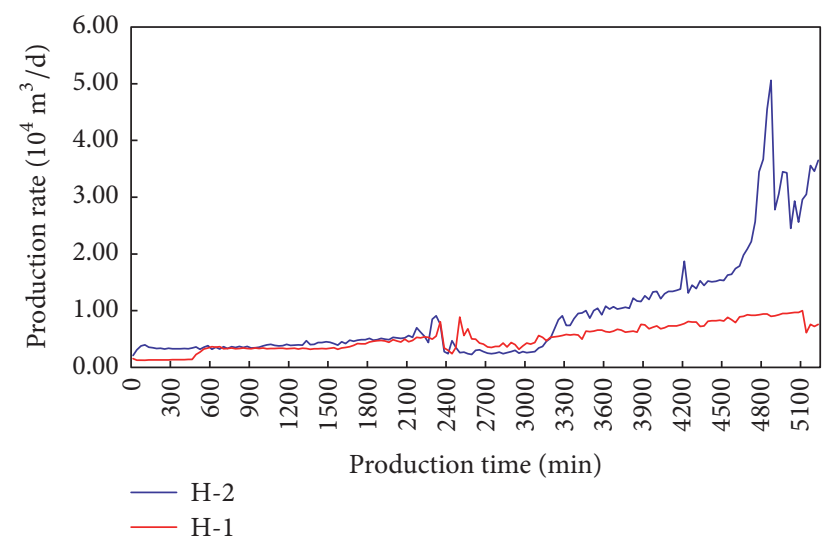

Figure 10: Postfracturing production rate for $\mathrm{H} 1$ and $\mathrm{H} 2$.

According to our previous study, ion concentrations in flow-back fluids are central to evaluating fracturing complexities after hydraulic fracturing. We use two shale gas wells in China as a case to explain the relationship between ion concentration and productivity after hydraulic fracturing. Platform-H is a development platform in southern China. The development formation is Longmaxi Shale. The depth of high-quality shale of the platform is around $3530 \mathrm{~m}$ and the thickness of the formation is between $50.6 \mathrm{~m}$ and $53.7 \mathrm{~m}$. Reservoir pressure gradient is about 1.96, which indicates a high level of reservoir pressure. The total organic content (TOC) of the formation is $4.90 \% \sim 6.28 \%$ according to well log interpretations. Gas content levels in the shale, as tested by geochemistry logging, range from $5.59 \sim 7.43 \mathrm{~m}^{3} / \mathrm{t}$. Porosity is approximately $7.34 \%$. There are two horizontal wells in this platform, and we refer to them as $\mathrm{H}-1$ and $\mathrm{H}-2$. The horizontal section of $\mathrm{H}-1$ is $1,450 \mathrm{~m}$, where the ratio of high-quality shale is $98.28 \%$. Staged slick water fracturing is performed in the $\mathrm{H}-1$ well, its stage number is 22, and its cluster number is 64 . Volumes of fracturing fluid and proppants used amount to $41,340 \mathrm{~m}^{3}$ and $1,660 \mathrm{~m}^{3}$, respectively. The horizontal section of the H-2 well is $1,415 \mathrm{~m}$, where the ratio of high-quality shale is $100 \%$. Staged slick water fracturing is performed in the $\mathrm{H}-2$ well. Its stage number is 22 and its cluster number is 65 . Volumes of fracturing fluid and proppants used amount to $38,510 \mathrm{~m}^{3}$ and $1,739 \mathrm{~m}^{3}$, respectively. The above data show that the same drilling and fracturing techniques are applied to these two wells in the same platform. Fracturing methods and scales used are the same for the two wells. Figures 10 and 11 show the daily production levels and $\mathrm{Cl}^{-}$content of flowback fluids.

Figure 10 shows that the production rates of the two wells become more similar early on at approximately $0.5 \times$ $10^{4} \mathrm{~m}^{3} / \mathrm{d}$. The production rate of $\mathrm{H}-2$ is much larger than that of $\mathrm{H}-1$ after 50 hours. The production rate of $\mathrm{H}-2$ is approximately three times that of $\mathrm{H}-1$, showing that the two wells have significantly different hydraulic fracturing effect. Figure 11 shows the $\mathrm{Cl}^{-}$content of flow-back fluid after fracturing retrieved through field ion concentration detection, which is used after fracturing and which is easy to apply. The results show that $\mathrm{Cl}^{-}$content levels for the wells vary.

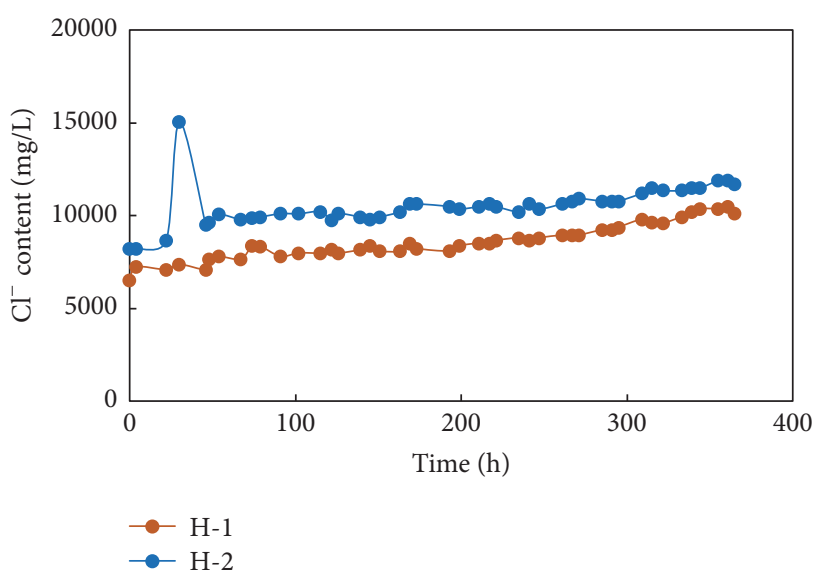

Figure 11: Postfracturing $\mathrm{Cl}^{-}$content levels in $\mathrm{H} 1$ and $\mathrm{H} 2$.

The $\mathrm{Cl}^{-}$content of $\mathrm{H}-2$ is approximately $20 \%$ greater than that of H-1. As the salinity of the formation and salinity of corresponding fracturing fluids are the same for the two wells, the $\mathrm{Cl}^{-}$content level found corresponds to the contact area between fracturing fluids and the formation, showing that the fracture system induced by hydraulic fracturing in $\mathrm{H}-2$ may be more complex than that induced in H-1. This field sample and our experiments show that the ion concentrations serve as an important auxiliary tool for evaluating the hydraulic fracturing effects.

\section{Conclusion}

Conductivity is a reflection of ion concentration change, which can be used to investigate interactions between fluids and rock. Ion concentrations in flow-back fluids are critical for evaluating fracturing complexity levels after hydraulic fracturing. Ion exchange between water and shale is controlled by water salinity, contact areas, and fracture density. Our field study shows that ion concentrations serve as an auxiliary tool method for estimating fracture complexity after hydraulic fracturing for shale gas wells in marine shale formations. The high salinity of marine shale brings about significant levels of ion exchange between formations and fracturing fluid. Ion concentrations can be used to determine the contact area between fracturing fluids and formations. Fracture systems are more complex when ion concentrations of flow-back rates are higher under similar conditions.

\section{Conflicts of Interest}

The authors declare no conflicts of interest.

\section{Authors' Contributions}

Each author made a contribution to the present paper. Yinghao Shen and Hongkui Ge developed the research questions. Zhaopeng Zhu collected the field data. Zhihui Yang conducted the experiments. 


\section{Acknowledgments}

This work was supported by the National Natural Science Foundation of China (Grants 51604287 and 51490652) and Science Foundation of China University of Petroleum-Beijing at Karamay (no. RCYJ2016B-01-001).

\section{References}

[1] D. M. Jarvie, R. J. Hill, T. E. Ruble, and R. M. Pollastro, "Unconventional shale-gas systems: the Mississippian Barnett Shale of north-central Texas as one model for thermogenic shale-gas assessment," AAPG Bulletin, vol. 91, no. 4, pp. 475499, 2007.

[2] Z. Pan, Y. Ma, L. D. Connell, D. I. Down, and M. Camilleri, "Measuring anisotropic permeability using a cubic shale sample in a triaxial cell," Journal of Natural Gas Science and Engineering, vol. 26, pp. 336-344, 2015.

[3] H. Dehghanpour, H. A. Zubair, A. Chhabra, and A. Ullah, "Liquid intake of organic shales," Energy and Fuels, vol. 26, no. 9, pp. 5750-5758, 2012.

[4] W. Yuan, X. Li, Z. Pan, L. D. Connell, S. Li, and J. He, "Experimental investigation of interactions between water and a lower silurian chinese shale," Energy and Fuels, vol. 28, no. 8, pp. 4925-4933, 2014.

[5] J. Li, X. Li, K. Wu et al., "Water sorption and distribution characteristics in clay and shale: effect of surface force," Energy and Fuels, vol. 30, no. 11, pp. 8863-8874, 2016.

[6] H. H. Liu, P. G. Ranjith, D. T. Georgi, and B. T. Lai, "Some key technical issues in modelling of gas transport process in shales: a review," Geomechanics and Geophysics for Geo-Energy and GeoResources, vol. 2, no. 4, pp. 231-243, 2016.

[7] D. Zhang, R. Pathegama Gamage, M. Perera, C. Zhang, and W. Wanniarachchi, "Influence of water saturation on the mechanical behaviour of low-permeability reservoir rocks," Energies, vol. 10, no. 2, p. 236, 2017.

[8] Y. Shen, H. Ge, C. Li et al., "Water imbibition of shale and its potential influence on shale gas recovery-a comparative study of marine and continental shale formations," Journal of Natural Gas Science and Engineering, vol. 35, pp. 1121-1128, 2016.

[9] Y. Shen, H. Ge, S. Su, D. Liu, Z. Yang, and J. Liu, "Imbibition characteristic of shale gas formation and water-block removal capability," Scientia Sinica Physica, Mechanica \& Astronomica, 2017.

[10] Y. Shen, H. Ge, M. Meng, Z. Jiang, and X. Yang, "Effect of water imbibition on shale permeability and its influence on gas production," Energy Fuels, vol. 31, no. 5, pp. 4973-4980, 2017.

[11] A. Hayatdavoudi, M. A. Boamah, A. Tavnaei, K. G. Sawant, and F. Boukadi, "Post Frac Gas Production through Shale Capillary Activation," in Proceedings of the SPE Production and Operations Symposium, Oklahoma City, Oklahoma, USA.

[12] A. Settari, R. Sullivan, and R. Bachman, "The Modeling of the Effect of Water Blockage and Geomechanics in Waterfracs," in Proceedings of the SPE Annual Technical Conference and Exhibition, San Antonio, Tex, USA.

[13] M. Sharma and S. Agrawal, "Impact of Liquid Loading in Hydraulic Fractures on Well Productivity," in Proceedings of the SPE Hydraulic Fracturing Technology Conference, The Woodlands, Tex, USA.
[14] J. Cai, X. Hu, B. Xiao, Y. Zhou, and W. Wei, "Recent developments on fractal-based approaches to nanofluids and nanoparticle aggregation," International Journal of Heat and Mass Transfer, vol. 105, pp. 623-637, 2017.

[15] X. Wang, S. Xiao, Z. Zhang, and J. He, Effect of Nanoparticles on Spontaneous Imbibition of Water into Ultraconfined Reservoir Capillary by Molecular Dynamics Simulation. Energies, 10, 506, 2017.

[16] B. Roychaudhuri, T. T. Tsotsis, and K. Jessen, "An experimental investigation of spontaneous imbibition in gas shales," Journal of Petroleum Science and Engineering, vol. 111, pp. 87-97, 2013.

[17] A. Javaheri, H. Dehghanpour, and J. M. Wood, "Tight rock wettability and its relationship to other petrophysical properties: A Montney case study," Journal of Earth Science, vol. 28, no. 2, pp. 381-390, 2017.

[18] Q. Meng, H. Liu, and J. Wang, "A critical review on fundamental mechanisms of spontaneous imbibition and the impact of boundary condition, fluid viscosity and wettability," Advances in Geo-energy Research, vol. 1, pp. 1-17, 2017.

[19] J. Cai, B. Yu, M. Zou, and L. Luo, "Fractal characterization of spontaneous co-current imbibition in porous media," Energy \& Fuels, vol. 24, no. 3, pp. 1860-1867, 2010.

[20] J. C. Cai and B. M. Yu, "A discussion of the effect of tortuosity on the capillary imbibition in porous media," Transport in Porous Media, vol. 89, no. 2, pp. 251-263, 2011.

[21] P. Fakcharoenphol, B. Kurtoglu, H. Kazemi, S. Charoenwongsa, and Y.-S. Wu, "The effect of osmotic pressure on improve oil recovery from fractured shale formations," in Proceedings of the SPE USA Unconventional Resources Conference 2014, pp. 456467, Woodlands, Tex, USA, April 2014.

[22] J. Wang and S. S. Rahman, "An Investigation of Fluid Leak-off Due to Osmotic and Capillary Effects and Its Impact on MicroFracture Generation during Hydraulic Fracturing Stimulation of Gas Shale," in Proceedings of the EUROPEC 2015, Madrid, Spain.

[23] E. Sadatshojaei, M. Jamialahmadi, F. Esmaeilzadeh, and M. H. Ghazanfari, "Effects of low-salinity water coupled with silica nanoparticles on wettability alteration of dolomite at reservoir temperature," Petroleum Science and Technology, vol. 34, no. 15, pp. 1345-1351, 2016.

[24] J. Yang, Z. Dong, Z. Yang, and M. Lin, "Wettability alteration by salinity and calcium bridge in a crude oil/brine/rock system," Petroleum Science and Technology, vol. 33, no. 19, pp. 1660-1666, 2015.

[25] P. Handren and T. Palisch, "Successful hybrid slickwaterfracture design evolution: an east texas cotton valley taylor case history," SPE Production and Operations, vol. 24, no. 3, pp. 415424, 2009.

[26] Z. Zhang and X. Li, Numerical Study on the Formation of Shear Fracture Network, vol. 9, 299, Energies, 4 edition, 2016.

[27] T. Cao, Z. Song, S. Wang, X. Cao, Y. Li, and J. Xia, "Characterizing the pore structure in the Silurian and Permian shales of the Sichuan Basin, China," Marine and Petroleum Geology, vol. 61, pp. 140-150, 2015. 

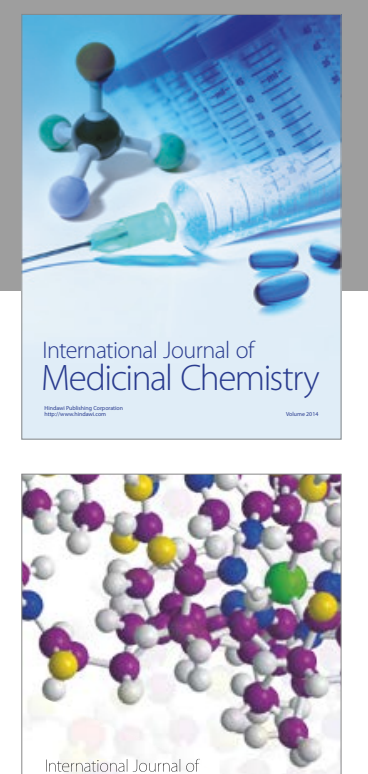

Carbohydrate Chemistry

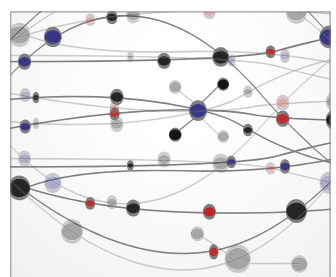

The Scientific World Journal
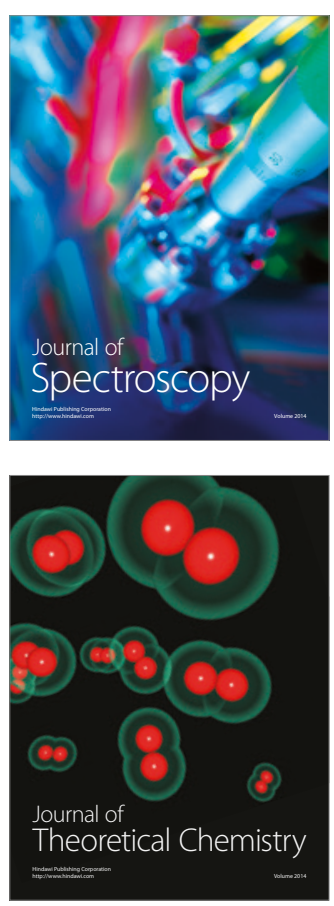
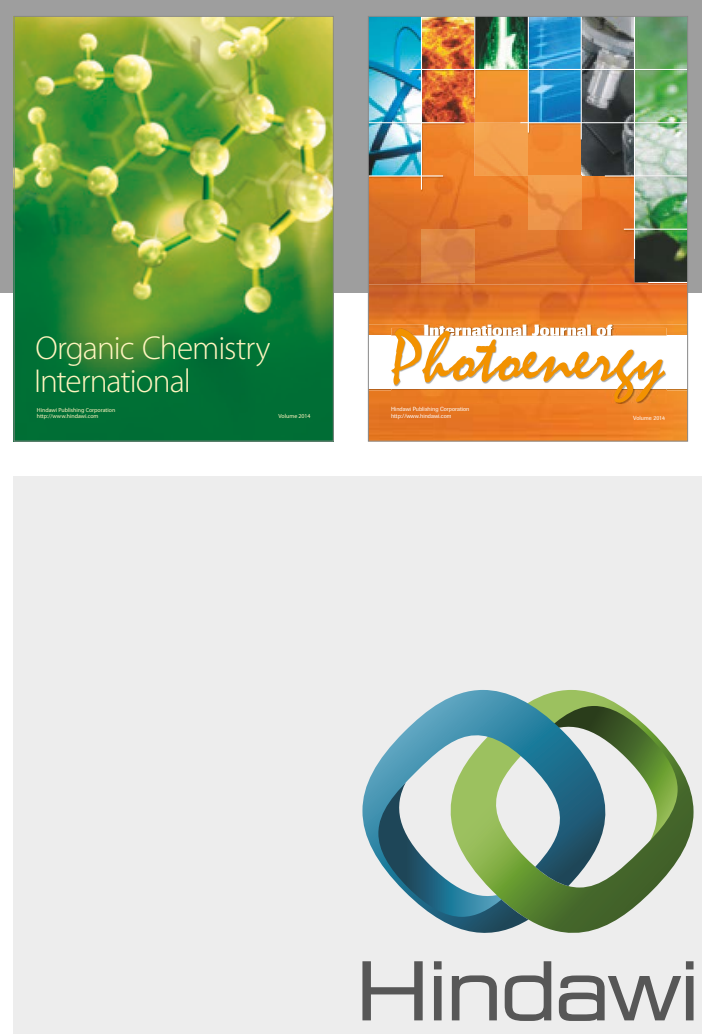

Submit your manuscripts at

https://www.hindawi.com

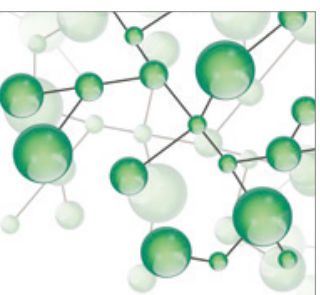

International Journal of

Inorganic Chemistry

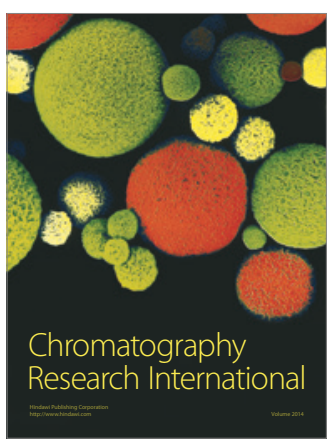

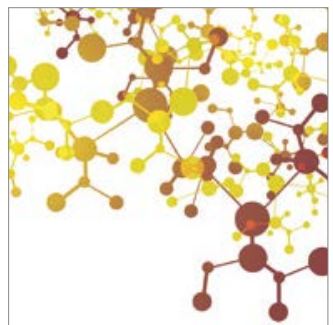

Applied Chemistry
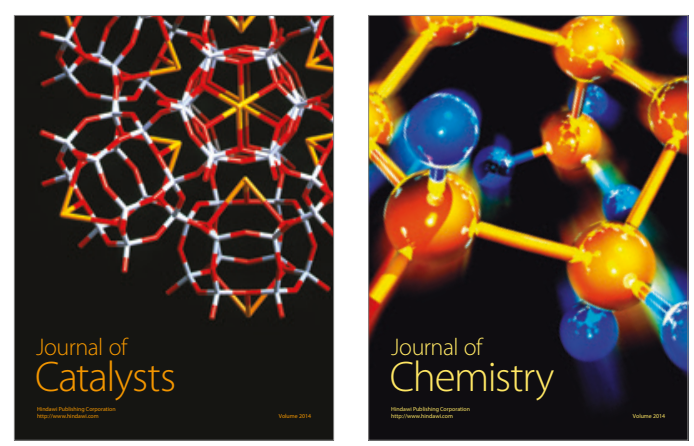
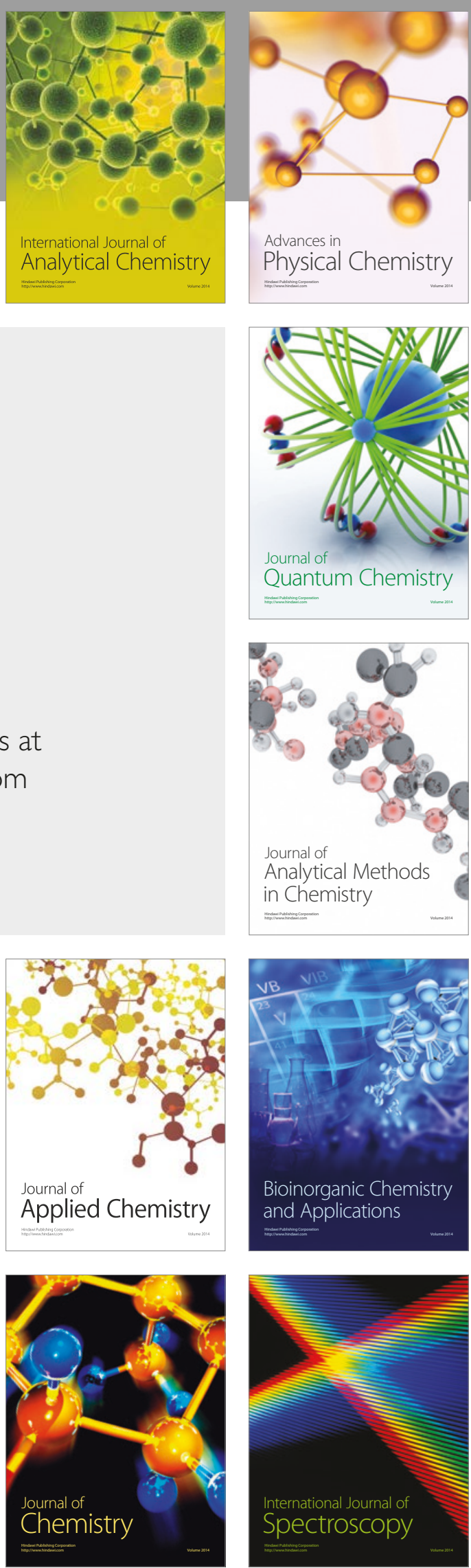